\title{
Costs to Physician Offices of Providing Medications to Medically Indigent Patients Via Pharmaceutical Manufacturer Prescription Assistance Programs
}

\author{
Patrick Clay, PharmD; Eric Vaught, BS; Alan Glaros, PhD; Stacy Mangum, PharmD; \\ Daniel Hansen; and Cameron C. Lindsey, PharmD, BC-ADM
}

\begin{abstract}
BACKGROUND: Prescription assistance programs (PAPs) are offered by pharmaceutical manufacturers to provide medications at no out-of-pocket cost to various categories of medically indigent patients. Some PAPs require only 1 application whereas others require as many as 4 applications per year per drug per patient, depending on the manufacturer's requirements.
\end{abstract}

OBJECTIVE: To measure the costs incurred by a medical clinic that provides chronic prescription medications via PAPs.

METHODS: This project was conducted in a free-standing, inner-city, Midwestern health clinic on the PAP application process for 1 representative drug for 32 pharmaceutical manufacturers that offered PAPs for drugs taken on a long-term basis for chronic conditions. Time and motion studies were conducted using a medical assistant with the greatest amount of PAP experience. Assessment of time-to-access and time-to-complete forms was performed outside of normal clinic business hours to avoid interruptions. Personnel time costs also included receipt and delivery of drug to the patient (drug distribution time), which were assessed during normal business hours for actual medications received for 10 patients and included the time required to notify the patient of the arrival of the drug and to dispense the medication to the patient. Supply costs for this PAP service included printing and copying costs. Submission costs associated with mailing or faxing the documents were determined and calculated using the price of materials only. Total application cost was calculated by adding the personnel time cost, supply cost, and submission cost. Annual PAP time was the time spent completing PAPs for 1 medication for 1 patient for 1 year. The time and resources required and the associated costs were aggregated separately for the pharmaceutical manufacturers that required 1,2, or 4 applications per drug per patient per year.

RESULTS: The total average application cost for all 32 companies was $\$ 25.18$ [SD, \$17.23]. Personnel time costs accounted for half or more of the total application cost, regardless of submission mode. The time to complete the form for any PAP was 0:06:20 [SD, 0:05:03] minutes with a range from 0:03:01 to 0:34:22 minutes. Printing costs were $\$ 0.20$ [SD, \$0.10] and copying costs were $\$ 1.96$ [SD, \$0.21]. Average supply costs were \$2.16 [SD, \$0.23]. Faxing versus mailing PAPs saved $\$ 17.90$ per application. Total annual clinic cost to assist patients in obtaining drugs through a PAP ranged from $\$ 10.42$ per patient for a drug that requires 1 application per year (15 manufacturers, $47 \%$ ) to $\$ 46.30$ per patient for a drug in a PAP that requires 4 (re)applications per year (12 manufacturers, 38\%). PAPs transmitted by mail required 0:49:18 [SD, 0:32:18] minutes, approximately 0:25:00 [SD, 0:21:00] minutes more than by fax (0:24:13 [SD, 0:11:32] minutes) or by Internet submissions $(0: 28: 20$ minutes), respectively.

CONCLUSION: The number of PAP applications required per patient per medication annually has the greatest impact on clinic time and financial resources. Application submission method also influences the overall costs of providing this service in the clinical setting. Medical clinics should base their decision to provide a PAP application service to patients on the time and costs associated over the course of 1 year and not on the 1-time application cost.
KEYWORDS: Pharmaceutical assistance program, Medically indigent, Costs; Primary care

J Manag Care Pharm. 2007;13(6):506-14

Copyright( 2007 , Academy of Managed Care Pharmacy. All rights reserved.

\section{What is already known about this subject}

- There is little information in the literature about the cost to physician offices that is incurred by providing prescription assistance programs (PAPs) to their patients.

\section{What this study adds}

- Total annual clinic cost to assist patients in obtaining drugs through a PAP ranges from $\$ 10.42$ per patient for a drug that requires 1 application per year (15 of 32 manufacturers, $47 \%$ ) up to $\$ 46.30$ per patient for a drug in a PAP that requires 4 (re)applications per year (12 of 32 manufacturers, 38\%).

66 hange is required so that alternative methods of providing and financing health care will extend coverage to low-income groups with high health care needs." ${ }^{\prime}$ Despite this proclamation, written 20 years ago by Dr. H.P. Ekern, the inability of the low-income or medically indigent population to pay for prescription drugs in the United States continues to be a barrier to receiving them. According to the Centers for Medicare \& Medicaid Services, spending on prescription drugs increased $5.8 \%$ in $2005 .^{2}$ As health care costs increase, and in particular, prescription drug costs, the disparities between the manufacturers' prices and the consumers' ability to pay for treatment will widen.

Medically indigent patients often do not meet requirements for Medicaid eligibility but are unable to afford private insurance coverage. In 2005, a family of 4 with an annual household income at or below $\$ 19,350$ was considered to be living below the poverty level..$^{3,4}$ However, $\$ 14,512$ (75\% of federal poverty level) was the cutoff for Medicaid eligibility.3., It is likely that this household could not afford private health insurance with prescription drug coverage, and it would fall into this medically indigent category. 


\section{Costs to Physician Offices of Providing Medications to Medically Indigent Patients Via Pharmaceutical Manufacturer Prescription Assistance Programs}

Knowing the status of health care coverage for patients is vital for providers to better serve their patients' medical needs. ${ }^{5,6}$ The benefits of providing prescription drugs to medically indigent patients who are otherwise unable to pay for them are well documented..$^{7-10}$ By complying with proper treatment regimens, patients are less likely to develop secondary disease associated with improper pharmaceutical compliance. ${ }^{11-13}$

Pharmaceutical company prescription assistance programs (PAPs) are designed to provide access to medications for those who are uninsured and unable to pay for their medications. Strum and colleagues found that offering the manufacturer PAP service to their patients with diabetes reduced lowdensity lipoprotein cholesterol and hemoglobin AlC values significantly. ${ }^{14}$ Additionally, patients could have access to more medications after they were enrolled in PAPs than when they were paying for their prescriptions themselves. Providing free or low-cost prescription drugs helps to improve medication adherence and reduces hospitalization rates as well as emergency room visits. ${ }^{11-14}$ The inability to pay for prescription drugs causes premature loss of life, loss of potential work time, and decreased quality of life. ${ }^{15}$

Research has shown that health care institutions, in addition to improving patient outcomes, can reduce bad debt claims resulting from uncompensated prescriptions by implementing their own PAPs. ${ }^{16}$ The cost of caring for the medically uninsured, indigent population usually falls on the local hospitals that treat these patients as an ambulatory outpatient service. ${ }^{17}$ Without access to needed medications, disease often progresses and emergency therapy is often needed to avoid acute complications or death. ${ }^{13}$ Therefore, physicians and medical groups that choose to forgo PAP participation because of administrative cost and/or time concerns may ultimately bear financial responsibility for these patients. ${ }^{18}$

In 2004, PAP access expanded to more than 22 million prescriptions, representing as much as $\$ 4$ billion in medications for patients. ${ }^{19}$ Despite these numbers, PAPs are often underused because of the complex application process. ${ }^{10}$ In fact, even using the heavily promoted www.pparx.org Web site, individuals are still instructed to go through their doctor's office to complete the application process: "Here are the assistance programs that you have selected. Some of the applications require that you contact the company, others need to be filled out and signed by your doctor. You can print the applications and details sheets for those programs that don't have applications available now or you can use our online application wizard to fill out all of the 'online available' applications at once. You can then print them and deliver them to your doctor."20

Most medically indigent patients are unable to participate in PAPs without assistance from health care professionals, many of whom lack time, training, or incentive. ${ }^{13}$ Some institutions have assigned personnel and established specific protocols to assist patients and providers in completing and submitting the PAP application forms and supporting documentation. ${ }^{7,10,14-15,18,21-30}$
This processing requires several steps, including completing the form in its entirety, providing an original signature by the prescriber, attaching the prescription and any required financial information, submitting this information to the manufacturer, and often requiring receipt of the medication at the prescriber's office between 2 to 8 weeks following submission of the PAP form. Additionally, the majority of PAPs provide a 3-month supply of medication at one time and require a new application for each subsequent quarterly supply; hence, 4 application submissions per year.

To date, there have been no published data describing personnel time and material costs incurred by organizations providing this service to patients. The objective of this study was to measure the costs incurred by a medical clinic that provides chronic prescription medications via PAPs.

\section{Methods}

This project was conducted in a free-standing, inner-city, Midwestern health clinic serving more than 13,000 medically indigent patients with more than 47,500 patient encounters in 2005-2006. ${ }^{31}$ The Kansas City Free Health Clinic has extensive experience using PAPs, having processed more than 3,250 PAP applications annually since 2001. ${ }^{32}$ A total of 143 unique medications from 39 pharmaceutical companies were initially considered for inclusion. Drug inclusion criteria were both approved by the U.S. Food and Drug Administration for use in a chronic medical condition that requires ongoing use (refills) to appropriately treat the condition and obtainable via a PAP.

In the early stages of data collection, it was determined that each pharmaceutical company had a unique application form but identical PAP requirements for different drugs within each company. On the basis of this finding, 1 representative drug from each company was used to generate project data. PAP forms vary among pharmaceutical manufacturers with respect to (1) qualification standards, (2) submission criteria, and (3) supporting documentation required. Therefore, the unique PAP application requirements from each company were analyzed individually using 1 drug from each manufacturer. Additionally, it is imperative to note that the necessary components to complete the application, the structure and organization of the application, and the number of signatures vary by each manufacturer, making it vital to assess the time necessary to complete each unique manufacturer's application. The time and resources required and the associated costs were aggregated separately for the pharmaceutical manufacturers that required 1,2 , or 4 applications per drug per patient per year.

Time and motion studies were conducted based on previously published methodologies. ${ }^{33-35}$ Medical assistants were assigned to complete PAP applications because they were (1) capable of completing the forms and (2) determined to have the lowest annual payroll cost per full-time equivalent salary. ${ }^{36}$ Only the medical assistant with the greatest amount of PAP experience 


\section{Costs to Physician Offices of Providing Medications to Medically Indigent Patients Via Pharmaceutical Manufacturer Prescription Assistance Programs}

was used for the time and motion study to eliminate the potential confounder of unfamiliarity with the PAPs. The study of time-to-access and time-to-complete forms was performed outside of normal clinic business hours. This method was used to avoid counting time costs associated with interruptions in workflow during a customary business day. Each application was completed 3 times by the experienced medical assistant and recorded by one of the authors (Mangum).

All applications were accessed via 1 of 2 Internet search engines-the Partnership for Prescription Assistance (www. pparx.org) or a nonprofit organization (www.needymeds.com). These 2 search engines were used because of their extensive inventory of PAP forms.

Total application cost was calculated by adding the personnel time cost, supply cost, and submission cost that are outlined and defined in Table 1. Personnel time cost from receipt of drug to delivery to the patient (drug distribution time) was assessed by time and motion observation performed by 1 of the authors (Mangum) of the actual medications received for 10 patients. This time measurement was the only component of personnel cost that was completed during normal clinic hours (drugs are not received on weekends). It is the medical clinic's policy to have all drugs delivered to the clinic and not directly to the patient because of the variable quality of housing situations among clinic patients and uncertainty regarding home receipt and accountability for the drugs. Once a medication was received, personnel, under the supervision of a physician, record, label, and store the drug at the clinic.

The oversight by the physician is an added safety check and one that is required by the clinic. Because the time from PAP application submission to receipt of medication may be as long as 8 weeks, this verification is designed to ensure no change in medication therapy has occurred since the request was forwarded to the manufacturer. Realizing that the medication is checked for accuracy by the drug manufacturer before shipping and that this added step in our clinic may be unique, we did not include the physician's time in the analysis. The other components of the drug distribution time portion of total personnel cost include the time required to notify the patient of the arrival of the drugs and the time to dispense the medication to the patient. This part of the PAP process is the same for all medications received and therefore does not differ among the PAPs.

Personnel time cost also included the time to access and complete forms. The information necessary to complete the forms was categorized into 5 general sections: (1) patient information, (2) health care provider information, (3) prescription

\section{TABLE 1 Description of Time and Material Costs}

\begin{tabular}{|c|c|c|}
\hline Cost Category & Components & Definitions \\
\hline \multirow[t]{3}{*}{ Personnel time costs ( $\$ 0.27$ per minute)* } & Time-to-access form (TAF, in minutes) & $\begin{array}{l}\text { Time from when personnel initially opened Internet } \\
\text { browser until documents and instructions were down- } \\
\text { loaded and successfully printed }\end{array}$ \\
\hline & Time-to-complete form (TCF, in minutes) & $\begin{array}{l}\text { Time spent filling out the required forms by health care } \\
\text { personnel }\end{array}$ \\
\hline & Drug distribution time (DDT, in minutes) & $\begin{array}{l}\text { Time spent notifying patient of arrival of drugs and } \\
\text { dispensing the medications }\end{array}$ \\
\hline \multirow[t]{2}{*}{ Supply costs $(\$)$} & Printing costs (PC, $\$ 0.05$ per page $) \dagger$ & Cost of printing 1 sheet of paper \\
\hline & Copying costs (CC, $\$ 0.07$ per page $) \dagger$ & Cost of copying 1 sheet of paper \\
\hline \multirow[t]{3}{*}{ Submission costs $(\$) \ddagger$} & Cost of mailing documents (CMD) $\S$ & Cost of envelope and postage used to mail documents \\
\hline & Cost of faxing documents (CFD, \$0.05 per page) $\dagger$ & Cost per page of submitting documentation via fax \\
\hline & Cost of Internet submission of documentation $(\$ 0.00)$ & $\begin{array}{l}\text { Cost to submit data electronically. No cost was assigned } \\
\text { since no materials were involved. }\end{array}$ \\
\hline Total application cost $(\$)$ & $\begin{array}{l}=\text { sum of personnel time costs }+ \text { supply costs }+ \text { submis- } \\
\text { sion costs }=[(\mathrm{TAF}+\mathrm{TCF}+\mathrm{DDT}) \times 0.27]+[(0.05 \times \text { num- } \\
\text { ber of pages printed })+(0.07 \times \text { number of pages copied })] \\
+[\mathrm{CMD} \text { or }(0.05 \times \text { number of pages faxed }) \text { or } \$ 0.00 \\
\text { (depending on route of documentation submission })]\end{array}$ & \\
\hline
\end{tabular}

\footnotetext{
* Based on mean hourly wage for medical assistants (\$12.21) plus benefits (\$4.23), resulting in total hourly cost of $\$ 16.24$ divided by 60 minutes. ${ }^{36}$

$\dagger$ Based on accepted market values.

\$ Submission costs included only the cost of submitting the document itself and do not include the cost of personnel time involved in the submission of those documents.

$\S$ United States Postal Service (USPS) standard priority mail envelope and base price were used to determine costs. Postage was also calculated using standard priority envelope and flat rate posted on the USPS Web site. ${ }^{37}$
} 


\section{Costs to Physician Offices of Providing Medications to Medically Indigent Patients Via Pharmaceutical Manufacturer Prescription Assistance Programs}

information, (4) financial and insurance documentation, and (5) other information such as phone calls, advocate enrollment, or credit checks (Table 2).

Supply cost for this PAP service included printing and copying costs. The same computer, printer, copier, fax, and charting system were used for all PAPs to ensure that the mechanical speed of different machines was not a factor in the final results (Table 1).

Submission cost associated with mailing ${ }^{37}$ or faxing the documents was determined and calculated using only the price of materials involved in submitting the documentation and did not include personnel time cost (Table 1).

As part of this clinic's submission process, personnel make 2 copies of the application and all supporting documents. One set of copies is given to the patient for his/her records, while the other set is placed in the patient's medical record. If the application is mailed, the original application and supporting documents are sent. Alternatively, if the application is faxed, the original documents are destroyed once successful transmission of the fax has occurred. For purposes of this study, the actual documents were not sent to the pharmaceutical company because patient information was fictitious. The times required by the pharmaceutical company to process the application, fill the prescription, and deliver the prescription were outside the scope of this study.

Annual PAP time was the time spent completing PAPs for 1 medication for 1 patient for 1 year. Twelve of the 32 companies (38\%) required a new application with each prescription order for 3 months (meaning 4 PAP forms per patient per year per medication), while 5 manufacturer PAPs (16\%) required 2 application forms per patient per year, and 15 manufacturers (47\%) required only 1 application each year (Table 3 ).

Time measurements were collected in an hour:minute:second format and depicted as such. Cost components were described in U.S. dollars and cents. Means and standard deviations were tabulated for all components. Differences in time and costs associated with submission methods and the number of applications required per year were analyzed by multivariate analysis of variance, followed by univariate analyses and post hoc testing, as appropriate. This project was approved by the Kansas City University of Medicine and Biosciences and the University of Missouri-Kansas City Institutional Review Boards.

\section{Results}

Thirty-nine pharmaceutical companies were originally considered for analysis. Data analysis was conducted on the 32 pharmaceutical companies that met the stated inclusion criteria. Total application cost is displayed in Figure 1. The average total application cost for all 32 companies was \$25.18 [SD, \$17.23] and ranged from $\$ 7.73$ (Bristol-Myers Squibb Company) to \$58.13 (GlaxoSmithKline PLC). Personnel time cost accounted for half or more of total application cost, regardless of submission

\section{TABLE 2 Typical Information Required to Complete} Prescription Assistance Program Forms

\begin{tabular}{l|l}
\hline Patient information* & 1) Name \\
& 2) Address \\
3) Phone number \\
4) Social Security number \\
5) Date of birth \\
6) Number in household \\
7) Employer information \\
8) Income/assets amount \\
9) Income source
\end{tabular}

Health care provider information 1 1) Physician's name

2) Medical specialty

3) State licensure number

4) DEA number

5) Medical clinic's address

6) Medical clinic's phone number

7) Medical clinic's fax number

8) Primary clinic contact

\begin{tabular}{l|l}
\hline Prescription information & 1) Drug \\
& 2) Daily dosing information \\
& 3) Directions for use \\
& 4) Quantity \\
& 5) Refills/duration of therapy \\
\hline Financial and insurance & 1) Tax forms \\
information $\dagger$ & 2) Pay stubs \\
& 3) Bank statements \\
& 4) Health insurance qualification \\
& 5) Social Security benefits statements \\
& 6) Medicaid denial letter \\
& 7) Alimony/child support \\
& 8) Unemployment \\
& 9) Veterans benefit \\
& 10) Pension/retirement \\
\hline Other information & 1) Phone calls \\
& 2) Advocate information \\
& 3) Patient credit checks \\
\hline
\end{tabular}

* To decrease variance and with consideration for HIPAA, all forms were completed with the same fictitious patient's information with the exception of GlaxoSmith-

Kline's "Bridges to Access," which requires actual patient information to receive a patient advocate number assignment.

+ One or more of these documents may be required by the pharmaceutical company.

For the purposes of this study, a fictitious patient would answer all questions and

have all necessary documentation available at the time of form completion.

$D E A=$ Drug Enforcement Administration; HIPAA = Health Insurance Portability and Accountability Act.

mode. The average time required to complete the forms for all PAPs was 0:06:20 [SD, 0:05:03] minutes with a range from 0:03:01 to 0:34:22 minutes. Drug distribution time was 0:06:35 [SD, 0:01:12]. Average printing costs were $\$ 0.20$ [SD, \$0.10] and photocopying costs were $\$ 1.96$ [SD, \$0.21]. Seventy-five percent $(n=24)$ of application packets were 4 pages long and required 10 pages of supporting documents. Collectively, this resulted in average supply costs of $\$ 2.16$ [SD, $\$ 0.23]$. The submission cost 


\section{Costs to Physician Offices of Providing Medications to Medically Indigent Patients Via Pharmaceutical Manufacturer Prescription Assistance Programs}

\begin{tabular}{|c|c|c|}
\hline \multicolumn{3}{|c|}{ Applications per Year* } \\
\hline 1 & 2 & 4 \\
\hline Abbott & Allergan & Aventis† \\
\hline AstraZeneca & Berlex & Biovail \\
\hline Bertek & Celltech & Boehringer-Ingelheim \\
\hline Bristol-Myers Squibb & Pfizer & Eli Lilly \\
\hline Dermik & XCEL & GlaxoSmithKline \\
\hline Forest & & Merck \\
\hline Genentech & & Novo Nordisk \\
\hline ICN & & Ortho \\
\hline Janssen & & Roche \\
\hline KOS & & Sankyo \\
\hline Novartis & & Schering \\
\hline Procter \& Gamble & & Wyeth \\
\hline \multicolumn{3}{|l|}{ Solvay } \\
\hline \multicolumn{3}{|l|}{ Takeda } \\
\hline TAP & & \\
\hline \multicolumn{3}{|c|}{$\begin{array}{l}\text { * Current at the time of data collection, June } 2006 . \\
\dagger \text { Aventis is now sanofi-aventis. } \\
P A P s=\text { prescription assistance programs. }\end{array}$} \\
\hline
\end{tabular}

incurred by mailing compared with faxing the application was a higher proportion of the total application cost. Faxing versus mailing PAPs saved $\$ 17.90$ dollars per application.

The average annual PAP time and costs are displayed in Figure 2. The annual PAP time was directly affected by the number of applications required per year for each medication. As can be seen in Figure 2, the increase in annual PAP time associated with multiple PAP applications for the same drug for the same patient had a directly proportional but not linear effect on annual PAP time and cost. Annual PAP time was also affected by method of submission. Mail submission $(n=27)$ required an average of 0:49:18 [SD, 0:32:18] minutes, approximately 0:25:00 and 0:21:00 minutes more than fax $(n=4,0: 24: 13$ [SD, 0:11:32] minutes) or Internet submissions ( $\mathrm{n}=1,0: 28: 20$ minutes), respectively. Personnel time associated with 4 applications accounted for $48.1 \%$ to $52.4 \%$ of total annual cost per drug per patient and varied by the submission method (Figure 2).

\section{Discussion}

Using office personnel to provide medications to patients via PAPs is a costly endeavor. Over 4 years beginning in 2001, our medical clinic spent $\$ 327,240$, or $\$ 81,835$ annually, for

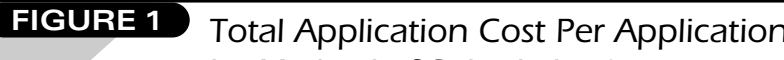
by Method of Submission*

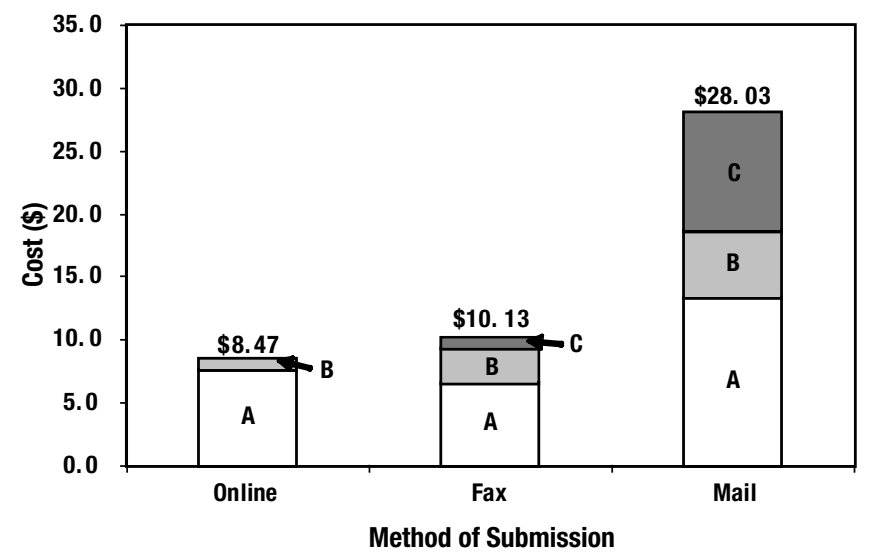

\begin{tabular}{|l|c|c|c|c|c|c|}
\hline \multicolumn{7}{|c|}{ Total Cost Per Application (\$) } \\
\hline & \multicolumn{2}{|c|}{ Internet (N = 1) } & \multicolumn{2}{c|}{ Fax (N = 4) } & \multicolumn{2}{c|}{ Mail (N = 27) } \\
\hline & $\begin{array}{c}\text { Mean } \\
{[S D]}\end{array}$ & $\begin{array}{c}\text { \% of } \\
\text { Total } \\
\text { Cost }\end{array}$ & $\begin{array}{c}\text { Mean } \\
{[\text { SD] }}\end{array}$ & $\begin{array}{c}\text { \% of } \\
\text { Total } \\
\text { Cost }\end{array}$ & $\begin{array}{c}\text { Mean } \\
{[S D]}\end{array}$ & $\begin{array}{c}\text { \% of } \\
\text { Total } \\
\text { Cost }\end{array}$ \\
\hline $\begin{array}{l}\text { Personnel } \\
\text { time cost (A) }\end{array}$ & 7.67 & 90.6 & $\begin{array}{c}6.56 \\
{[3.12]}\end{array}$ & 64.7 & $\begin{array}{c}13.34 \\
{[8.74]}\end{array}$ & 47.6 \\
\hline $\begin{array}{l}\text { Supply cost } \\
\text { (B) }\end{array}$ & 0.80 & 9.4 & $\begin{array}{c}2.70 \\
{[1.08]}\end{array}$ & 26.6 & $\begin{array}{c}5.28 \\
{[3.13]}\end{array}$ & 18.8 \\
\hline $\begin{array}{l}\text { Submission } \\
\text { cost (C) }\end{array}$ & 0.00 & 0.0 & $\begin{array}{c}0.88 \\
{[0.35]}\end{array}$ & 8.7 & $\begin{array}{c}9.41 \\
{[5.58]}\end{array}$ & 33.6 \\
\hline $\begin{array}{l}\text { Total applica- } \\
\text { tion cost }\end{array}$ & 8.47 & 100.0 & $\begin{array}{c}10.13 \\
{[4.55]}\end{array}$ & 100.0 & $\begin{array}{c}28.03 \\
{[17.24]}\end{array}$ & 100.0 \\
\hline
\end{tabular}

* A multivariate analysis of variance on time and cost was performed for fax and mail submissions; Internet submission data were not entered into this analysis because there was only one company that used this method. This analysis showed a significant effect of submission method on time and costs, $F(2,28)=6.73, P<.010$, partial eta-squared $=0.325$. Univariate tests did not demonstrate a significant effect of submission method on time and a marginally significant effect $(P=0.051)$ on cost.

this service. ${ }^{32}$ Not surprisingly, PAPs that required more than 1 application per patient per year and had to be mailed were the most costly. Mailed applications had an average total cost of nearly 3 times the cost of applications submitted by fax, $\$ 28.03$ versus $\$ 10.13$. PAPs that required 4 applications per drug per patient per year had an annual cost that was more than 4 times the cost (\$46.30) of a manufacturer that required 1 application per year $(\$ 10.42)$.

It is important to note that a PAP that requires 4 applications per year does not simply require completing the "once-annual" application and submitting it 4 times. Instead, it involves 


\section{Costs to Physician Offices of Providing Medications to Medically Indigent Patients Via Pharmaceutical Manufacturer Prescription Assistance Programs}

collecting updated information from the patient (Table 2) and repeating the entire process 3 more times. Each PAP requires a different amount of information necessary to complete the application; hence, each manufacturer's application is unique. One cannot simply take the cost necessary to complete the application for a company that requires only a once-annual submission and multiply it by the number of each reapplication for another company and expect to appropriately judge the cost of time to complete the application. These estimated PAP costs were minimized through the use of lower-payroll personnel, time of observation (e.g., outside of normal clinic hours for some of the observations), and personnel familiarity with the various PAP process and information requirements.

Support for the personnel time and cost findings for this study can be found in the literature. Previous research conducted by Richardson and Basskin ${ }^{30}$ in a survey of 118 safety-net providers, of which 52 were in a clinic setting, illustrated that respondents reported that paper applications required an average of 1.1 hours, $36 \%$ more than the average 0.81 hours in the present study, and 0.8 hours per electronic submission, twice the 0.4 hours found in the present study. Sarrafizadeh and colleagues ${ }^{24}$ estimated the personnel time in a private ambulatory care clinic and found that 1 medication order for a PAP used 1 hour of a pharmacist's time. Coleman and associates ${ }^{35}$ conducted a study in an inpatient setting and reported average personnel time, tracking time via a time log, of 2.25 hours per day over 129 program working days to process 96 PAP applications, which resulted in approximately 3 hours per application.

Our study directly measured the time necessary for personnel to complete applications, whereas these previous studies used only estimates of personnel time. Another potential for the variance in PAP time requirements across studies may be explained in part by our methods, in that the time and motion studies for completing the applications were conducted outside of normal clinic hours. Weiner and colleagues reported 6-month operation costs of $\$ 110,537$ for a broad-scope patient assistance program in 1999-2000 that included a PAP service, and drug cost savings of $\$ 237,985$ that included a PAP cost offset in free goods of $\$ 31,028(13 \%) .{ }^{10}$ This study included overhead, higher-salaried personnel without breakdown by type of personnel, and did not report the volume of PAP applications. This broader-scope patient assistance program to obtain lower-cost medications had an operating cost, if annualized, of $\$ 958$ per patient, delivering about $\$ 2,060$ per year in drug cost savings or a savings-to-cost ratio of about 2.2-to-1.

Meaningful comparison of our findings and prior studies were made difficult as a result of methodological differences. Other programs, for instance, charge a fee for each prescription filled in the PAP to offset expenses for the program. ${ }^{30}$ More important, before the present study, physicians were unable to use these data to predict the feasibility of providing this service in their own setting because a projected cost per PAP had not been

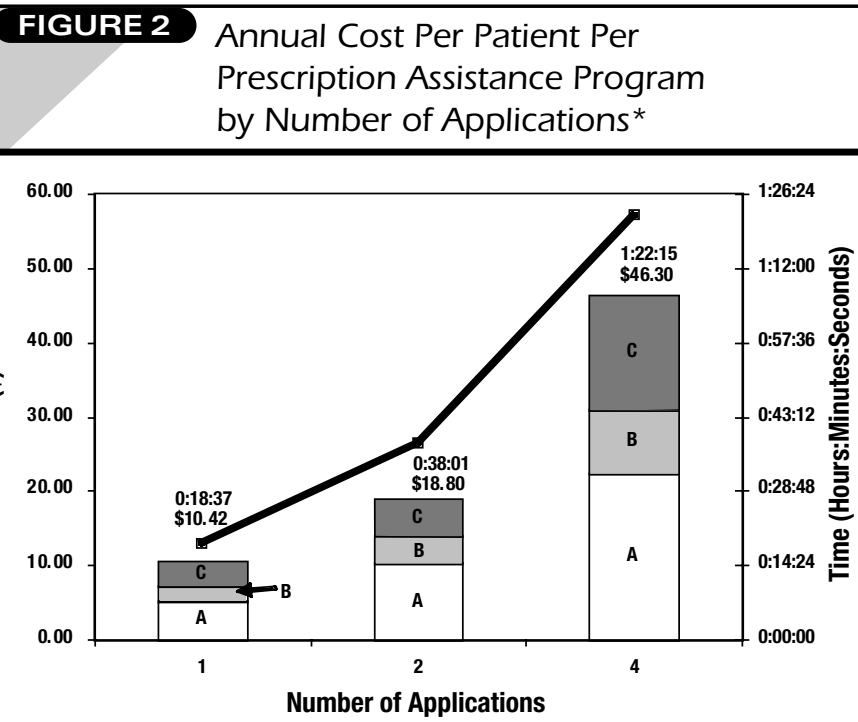

* The line represents the annual PAP time.

\begin{tabular}{|c|c|c|c|c|c|c|}
\hline \multicolumn{7}{|c|}{ Annual PAP Cost (\$) } \\
\hline & \multicolumn{2}{|c|}{$\begin{array}{l}1 \text { Application } \\
(\mathrm{N}=15)\end{array}$} & \multicolumn{2}{|c|}{$\begin{array}{c}2 \text { Applications } \\
(\mathrm{N}=5)\end{array}$} & \multicolumn{2}{|c|}{$\begin{array}{l}4 \text { Applications } \\
(\mathrm{N}=12)\end{array}$} \\
\hline & $\begin{array}{l}\text { Mean } \\
{[S D]}\end{array}$ & $\begin{array}{l}\% \text { of } \\
\text { Total } \\
\text { Cost }\end{array}$ & $\begin{array}{l}\text { Mean } \\
{[S D]}\end{array}$ & $\begin{array}{l}\% \text { of } \\
\text { Total } \\
\text { Cost }\end{array}$ & $\begin{array}{l}\text { Mean } \\
\text { [SD] }\end{array}$ & $\begin{array}{l}\% \text { of } \\
\text { Total } \\
\text { Cost }\end{array}$ \\
\hline $\begin{array}{l}\text { Personnel } \\
\text { time cost (A) }\end{array}$ & $\begin{array}{c}5.04 \\
{[0.30]}\end{array}$ & 48.4 & $\begin{array}{l}10.29 \\
{[1.74]}\end{array}$ & 54.7 & $\begin{array}{l}22.26 \\
{[4.09]}\end{array}$ & 48.1 \\
\hline $\begin{array}{l}\text { Supply cost } \\
\text { (B) }\end{array}$ & $\begin{array}{c}2.16 \\
{[0.00]}\end{array}$ & 20.7 & $\begin{array}{c}3.62 \\
{[1.57]}\end{array}$ & 19.2 & $\begin{array}{c}8.64 \\
{[0.00]}\end{array}$ & 18.6 \\
\hline $\begin{array}{l}\text { Submission } \\
\text { cost (C) }\end{array}$ & $\begin{array}{c}3.22 \\
{[1.30]}\end{array}$ & 30.9 & $\begin{array}{c}4.90 \\
{[3.87]}\end{array}$ & 26.1 & $\begin{array}{l}15.40 \\
{[0.00]}\end{array}$ & 33.3 \\
\hline $\begin{array}{l}\text { Total applica- } \\
\text { tion cost }\end{array}$ & $\begin{array}{l}10.42 \\
{[1.36]}\end{array}$ & 100.0 & $\begin{array}{l}18.80 \\
{[6.39]}\end{array}$ & 100.0 & $\begin{array}{l}46.30 \\
{[4.09]}\end{array}$ & 100.0 \\
\hline
\end{tabular}

* A multivariate analysis of variance showed a significant effect of application number on time and costs, $F(4,56)=61.126, P<0.001$, partial eta-squared $=0.814$. Univariate tests conducted separately on time and cost both showed significant effects, $F(2,29)=147.16$ and 343.127, partial eta-squared $=0.910$ and 0.959 for time and cost, respectively, $P<0.001$. Post hoc tests using Bonferroni's test each showed that the time and cost of 1,2, and 4 applications was significantly different from each other.

determined. As an example of the value of the present study, it is possible to estimate a projected increase of $206 \%$ in personnel costs compared with our results if a registered nurse is used rather than a medical assistant. ${ }^{36}$

It should be noted that all of the companies that participate in PAPs are brand-name drug companies. In community practice, there is often a therapeutically equivalent generic alternative in the same drug class as the prescribed medication. In theory, prescribing the generically available alternative in place of the 


\section{Costs to Physician Offices of Providing Medications to Medically Indigent Patients Via Pharmaceutical Manufacturer Prescription Assistance Programs}

brand-name drug would lower the overall health care cost for the patient. ${ }^{38}$ However, some of these patients who use PAP programs have difficulty even paying for generic drugs, which would lead to noncompliance, disease progression, and/or increased overall health care costs. This is why the prescribing of brand-name drugs and the use of PAPs are essential for the care of some clinic patients.

There are some alternatives to providing PAPs in medical offices. Two Internet sites (www.pparx.org and www.rxassist.org) provide eligibility information and downloadable prescription assistance applications. These sites are efficient to use in locating forms and instructions compared with the alternative method of trying to find PAP information on each individual pharmaceutical Web site. The features of these Web sites improve the initial access to the manufacturer's application and provide accurate manufacturer contact information but do not eliminate the majority of time and costs that must be assumed by medical offices to provide PAP services for patients.

Outsourcing assistance for patients to obtain drugs through PAPs is another option, since not every medical practice can afford to provide the necessary personnel and materials. As such, others have reported savings of $\$ 27,000$ per year by using an outside source to assist patients in completing PAPs. ${ }^{10}$ Locally, community health centers and the United Way have developed programs to improve access to medicines for the medically indigent. ${ }^{39}$ Physicians in communities with these resources available can provide contact information and patient brochures about these services in their offices. In many cases, these organizations already have the established clerical support in place and require minimal charge, if any, to provide application assistance. Internet groups such as The Medicine Program and Medicine Bridge offer patients help in obtaining and completing PAPs, albeit for a fee. ${ }^{40,41}$ More recently, Patient Assistance Program Solution (www.paprx.com) has begun offering a software package to assist with the PAP process. ${ }^{42}$ No formal comparison has been conducted, to date, among the various assistance programs.

Recently, another local metropolitan free health clinic incorporated the use of a computerized program to assist with the PAP process. This clinic is staffed completely by volunteers and open only 1 night each week. In 2005, the clinic served more than 350 patients in 26 different zip codes. ${ }^{43}$ Since the clinic opened in 2000, more than 6,000 patient visits and more than $\$ 1.3$ million in free medications have been donated by pharmaceutical PAPs, with more than 1,900 PAP applications processed in $2006 .{ }^{44}$ This clinic serves a similar population to the one described in the present study, and it is possible to estimate from our data the time that might be saved by using a computerized program for the PAP process. From our data in Table 2 and assuming that the supply and submission cost would be similar between the 2 clinics because the computer system did not change the submission modalities or the additional forms necessary to process PAPs forms, the time to complete an application is reduced to 0:02:13 minutes compared with more than 0:06:00 minutes with manual writing. ${ }^{45}$ This time savings is offset by the upfront personnel time that is required to input all the data for each patient into the computer system and to keep it updated, as well as the cost of the software and annual renewal fees. While all the staff are volunteers in that comparison free health clinic so there is no personnel time cost, this alternative method of completing PAPs may provide additional information to clinics evaluating the feasibility of providing patients with assistance in using PAPs.

"Development of a 'universal' PAP application process would greatly benefit patients and health care providers as well as reduce personnel time required to complete individual applications," according to Chishom and DiPiro. ${ }^{13}$ Often the reasoning behind making the process as complex as it is lies in the pharmaceutical companies' requirement to determine income eligibility and if alternative sources of funding are available to the patient. However, the need to verify eligibility more than once a year seems questionable. Nevertheless, having the forms available to patients in a more universal, standardized format and without requiring prescriber information other than the prescription itself would solve much of the problems and the professional time required.

Requiring the prescriber's signature on the individual application to verify the information provided on the application and certify that there is no falsification of data seems unnecessarily burdensome. This requires time of the clinic staff and prescriber as well as the patient to have the prescriber give an additional signature if the clinic does not offer a PAP service. This requirement of a second signature by the prescriber on the PAP application makes it impossible for a patient to take the prescription from the prescriber, download the form from a public place, and submit the PAP directly. Rather, the patient must make a second trip to the prescriber for his or her signature to certify that the PAP form submitted by the patient is truthful and complete.

If the application is approved by the pharmaceutical manufacturer and the medication is mailed, the majority of manufacturers mail the medication directly to the prescriber. This requires that someone at the medical clinic accept the mailed prescription and contact the patient. Then the indigent patient must again incur a travel expense to pick up the medication. While the cost of medications provided by pharmaceutical manufacturers helps to control chronic illness and reduce acute care expenditures, the cost to providers, clinic staff, and patients who use the PAPs reduces the total cost savings from PAPs.

\section{Limitations}

The first limitation is that the time and motion study was performed outside of normal business hours to (1) avoid interference with clinic operations and (2) isolate the time 


\section{Costs to Physician Offices of Providing Medications to Medically Indigent Patients Via Pharmaceutical Manufacturer Prescription Assistance Programs}

actually necessary for performing the tasks related to fulfilling the requirements for PAP application, receipt, and distribution of drugs to patients. This method may underestimate the actual time required by clinic personnel to complete the work required by PAP facilitation for patients. Second, the staff member with the most experience in completing and submitting particular PAPs was observed, which would tend to underestimate the average time required if several staff members rather than a specific, experienced staff member were assigned responsibility for PAPs. Third, the medical assistant with experience in PAP applications had the lowest payroll cost among the professional staff in the clinic, and therefore our cost estimates would tend to be lower than would other medical clinics that use higher-cost professionals to provide PAP services.

Fourth, the time and motion observations were not performed by experts and included observation of only 1 medical assistant and should therefore be considered estimates. Fifth, the reliability of the time estimates is affected by the small number of observations-3 observations for the time estimates made in off-hours and a total of 10 observations for direct distribution time.

\section{Conclusion}

The number of PAP applications required per patient per medication per year has the greatest impact on clinic time and financial resources. The application submission method (i.e., mail, fax, or Internet) also influences the overall costs of providing this service in the clinic setting. Because of the variable number of PAP applications required by different drug manufacturers, medical clinics should base their decision to provide assistance with PAP applications on the time and associated costs over the course of 1 year and not on the 1 -time application cost.

\section{Authors}

PATRICK CLAY, PharmD, is director of clinical research and an associate professor of medicine; ERIC VAUGHT, BS, is a fourthyear medical student; and ALAN GLAROS, PhD, is associate dean for basic medical sciences, Kansas City University of Medicine and Biosciences; STACY MANGUM, PharmD, is director of pharmacy, Missouri Southern Healthcare, Dexter; DANIEL HANSEN is a doctor of pharmacy candidate, University of Missouri-Kansas City; CAMERON C. LINDSEY, PharmD, BC-ADM, is an associate professor of pharmacy practice, University of Missouri-Kansas City.

AUTHOR CORRESPONDENCE: Patrick Clay, PharmD, Director, Clinical Research, and Associate Professor of Medicine, Kansas City University of Medicine and Biosciences, Dybedal Clinical Research Center, 1750 Independence Ave., Kansas City, MO 64106-1953. Tel: (816) 283-2335; Fax: (816) 283-2357; E-mail: pclay@kcumb.edu

\section{ACKNOWLEDGMENTS}

We acknowledge Craig Dietz, DO, Kansas City Free Health Clinic, Kansas City, MO; Melita Croom, PharmD, MPA, University of Missouri-Kansas City Drug Information Center, Kansas City, MO; Semaneh Wilkinson, PharmD, University of Kansas Medical Center, Kansas City, KS; and Kelly Busschler, BS, medical student, Kansas City University of Medicine and Biosciences, Kansas City, MO, for their support and assistance with this project.

\section{DISCLOSURES}

No outside funding supported this study. The authors disclose no potential bias or conflict of interest relating to this article. Portions of this research were presented as a poster, "Cost of Providing Medications Via Prescription Assistance Programs to Medically Indigent Patients," at a student session at the 49th Annual American Osteopathic Medical Association Meeting, October 25, 2005, in Orlando, FL (Abstract \#91).

Author Patrick Clay served as principal author of the study. Study concept and design were contributed by Clay and author Stacy Mangum. Data collection was primarily the work of author Eric Vaught, with input from Mangum and Clay; data interpretation was primarily the work of Vaught, with input from Clay and author Alan Glaros. Writing of the manuscript was the work of authors Daniel Hansen and Cameron C. Lindsey and Clay and Garos; its revision was the work of Hansen, Clay, and Lindsey.

\section{REFERENCES}

1. Ekern HP. Missouri's medically indigent. Missouri Med. 1987;84:115-16.

2. Office of the Actuary at the Centers for Medicare \& Medicaid Services. Available at: www.cms.hhs.gov/NationalHealthExpendData/downloads/ highlights.pdf. Accessed May 31, 2007

3. U.S. Dept. of Health and Human Services. The 2005 HHS poverty guidelines. Available at: http://aspe.hhs.gov/poverty/05poverty.shtml. Accessed May 31, 2007

4. Missouri Department of Social Services. Federal poverty guidelines Available at: http://www.dss.mo.gov/fsd/povlev.htm. Accessed May 31, 2007.

5. Montemayer K. How to help your low-income patients get prescription drugs. Fam Pract Manag. 2002;9:51-56

6. Heisler M, Wagner T, Piette J. Clinician identification of chronically ill patients who have problems paying for prescription medications. Am J Med. 2004;116:753-58

7. Adams D, Wilson AL. Structuring an indigent care pharmacy benefit program. Am J Health Syst Pharm. 2002;59:1669-75.

8. Nykamp D, Ruggles D. Impact of an indigent care program on use of resources: experiences at one hospital. Pharmacotherapy. 2000;20:217-20.

9. Mounts VL, Ringenberg DG, Rhees K, Partridge C. Implementation of a patient medication assistance program in a community pharmacy setting. J Am Pharm Assoc. 2005;45:76-81.

10. Weiner S, Dischler J, Horvitz C. Beyond pharmaceutical manufacturer assistance: broadening the scope of an indigent drug program. Am J Health Syst Pharm. 2001;58:146-50.

11. Parker-Oliver D, Crandall L. Medications assistance program: University of Missouri Health Care Department of Social Services. Health Soc Work. 2002;27:303-06

12. Heisler M, Langa KM, Eby EL, Fendrick AM, Kabeto MU, Piette JD. The health effects of restricting prescription medication use because of cost. Med Care. 2004:42:626-34

13. Chishom MA, DiPiro JT. Pharmaceutical manufacturer assistance programs Arch Intern Med. 2002;162:780-84.

14. Strum MW, Hopkins R, West DS, Harris BN. Effects of a medication assistance program on health outcomes in patients with type 2 diabetes mellitus. Am J Health Syst Pharm. May 15, 2005;62(10):1048-52. 


\section{Costs to Physician Offices of Providing Medications to Medically Indigent Patients Via Pharmaceutical Manufacturer Prescription Assistance Programs}

15. Dent LA, Stratton TP, Cochran GA. Establishing an on-site pharmacy in a community health center to help indigent patients access medications and to improve care. J Am Pharm Assoc. 2002;42:497-507.

16. National Association of Public Hospitals and Health Systems. What is a safety-net hospital? Available at: www.naph.org/Content/ContentGroups/ Publications1/WhatIsASafetyNetHospital.pdf. Accessed May 31, 2007.

17. Weissman JS, Gaskin DJ, Reuter J. Hospitals' care of uninsured patients during the 1990s: the relation of teaching status and managed care to changes in market share and market concentration. Inquiry. 2003;40:84-93.

18. Sagall R. Helping patients help themselves. Fam Pract Manag. 2005;12:24.

19. The Pharmaceutical Research and Manufacturers of America. Getting the word out on patient assistance programs: Straight talk from Billy Tauzin. Available at: www.phrma.org/about_phrma/. Accessed May 30, 2007.

20. Partnership for Prescription Assistance. Available at: https://www.pparx. org/ReviewResults.php. Accessed July 12, 2007.

21. Lurk JT, DeJong DJ, Woods TM, Knell ME, Carroll CA. Effects of changes in patient cost sharing and drug sample policies on prescription drug costs and utilization in a safety-net-provider setting. Am J Health Syst Pharm. 2004:61:267-72.

22. Saenz-Duke K, Raube K, Levens-Lipton H. Patient-assistance programs: assessment of and use by safety-net clinics. Am J Health Syst Pharm. 2005;62:726-31.

23. Viale PH, Mister S. Utilization of medication-assistance programs for medically uninsured patients: one public teaching hospital's experience. Clin J Oncol Nurs. 2001;5:247-52.

24. Sarrafizadeh M, Waite NM, Hobson EH, Migden H. Pharmacist-facilitated enrollment in medication assistance programs in a private ambulatory care clinic. Am J Health Syst Pharm. 2004;61:1816-20.

25. Chisholm MA, Tackett KL, Kendrick BD, DiPiro JT. Assistance programs available for medications commonly used in transplant patients. Clin Transplant. 2000;14:269-81.

26. Chisholm MA, Reinhardt BO, Vollenweider LJ, Kendrick BD, DiPiro JT. Medication assistance programs for uninsured and indigent patients. Am J Health Syst Pharm. 2000;57:1131-36.

27. Harmon GN, Lefante J, Roy W, et al. Outpatient medication assistance program in a rural setting. Am J Health Syst Pharm. 2004;61:603-07.

28. Hotchkiss BD, Person C, Listano R. Pharmacy coordination of an indigent care program in a psychiatric facility. Am J Health Syst Pharm. 1998;55:1293-96.

29. Decane BE, Chapman J. Program for procurement of drugs for indigent patients. Am J Hosp Pharm. 1994;51:669-71.
30. Richardson K, Basskin LE. Use of drug manufacturers' patient assistance programs by safety net providers. Am J Health Syst Pharm. 2002;59:1105-09.

31. Kansas City Free Health Clinic: 2005-2006. Annual report. Available at: http://www.kcfree.org/pdf/annual_report/KCFree_2005-2006_Report.pdf. Accessed May 29, 2007.

32. Kansas City Free Health Clinic, Dept. of General Medicine. Internal data.

33. Smith MW, Barnett PG. Direct measurement of health care costs. Med Care Res Rev. 2003;60:74s-91s.

34. Chishom MA, Vollenweider LJ, Mulloy LL, Wynn JJ, Wade WE, DiPiro JT. Cost-benefit analysis of a clinical pharmacist-managed medication assistance program in a renal transplant clinic. Clin Transplant. 2000;14:304-07.

35. Coleman CI, Reddy P, Quercia RA, Cousse G. Cost-benefit analysis of a pharmacy-managed medication assistance program for hospitalized indigent patients. Am J Health Syst Pharm. 2003;60:378-82.

36. U.S. Dept. of Labor, Bureau of Labor Statistics. 1999 national occupational employment and wage estimates: Healthcare practitioners and technical occupations. Available at: http://www.bls.gov/oes/1999/oes290000.htm. Accessed June 1, 2007.

37. U.S. Postal Service. Priority mail price sheet. Available at: www.usps.com. Accessed May 29, 2007.

38. Stebbins MR, Kaufman DJ, Lipton HL. The PRICE Clinic for low income elderly: a managed care model for implementing pharmacist-directed services. J Manag Care Pharm. 2005;11(4):333-41. Available at: http://www.amcp.org/ data/jmcp/contemporary_333_341.pdf. Accessed May 29, 2007.

39. United Way of Greater Mercer County. Accessing healthcare. Available at: http://www.uwgmc.org/ci_building.html. Accessed May 29, 2007.

40. The Medicine Program.com. Free medicine program. Available at: http:// www.themedicineprogram.com/free-medicine.html. Accessed June 12, 2007.

41. Medicine Bridge.com. Medicine bridge benefits. Available at: http:// medicinebridge.com/benefits.html. Accessed June 12, 2007.

42. Patient assistance program solution-PAPrx. Available at: http://www. paprx.com/. Accessed June 14, 2007.

43. Jackson County Free Health Clinic. 2005 statistics. Available at: http:// www.jcfhc.org. Accessed June 1, 2007.

44. Jackson County Free Health Clinic. Internal data.

45. Busschler K, Clay PG, Lindsey C. Cost to complete PhRMA patient/ medication assistance program (PAP) applications using "money saving" software. Poster presented at: 2007 Missouri Society of Health Systems Pharmacy Spring Meeting; March 23-24, 2007; St. Louis, MO. 